\title{
Universidade de Brasília: filha da utopia de reparação
}

Helena Bomeny*

Cada país tem que ter o seu projeto. Esse projeto necessita ser formulado. As leis precisam ser feitas. Diante disso, eu quero me obrigar a acreditar na Utopia Brasil...

Darcy Ribeiro (1998: 101).

Resumo: Este artigo trata da criação da Universidade de Brasília e do protagonismo de Darcy Ribeiro nesse empreendimento. Três momentos na historia da universidade marcam sua narrativa correspondentes a três tempos que ritmaram a criação da universidade: tempo da utopia; tempo do gabinete; tempo da distopia.

Palavras-chave: Universidade de Brasília, Darcy Ribeiro..

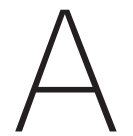

elaboração deste texto beneficiou-se de um retorno à documentação do acervo Darcy Ribeiro, depositado na UnB. A leitura da correspondência entre Darcy e um grupo de intelectuais no período compreendido entre 1958 e 1968 - os dez anos que definiram o próprio curso da universidade - sinaliza a dimensão especial conferida ao projeto frente às demais instituições de ensino superior no Brasil. Para caber no espaço comprimido deste texto, sugiro o que metodologicamente defini como três tempos:

Tempo I: a utopia de nação invade a universidade;

Tempo II: a utopia chega ao gabinete;

Tempo III: a distopia de nação refaz a universidade.

Os tempos são precedidos por fios que antecederam o engenho e definiram os passos de criação da universidade.

\author{
* Professora titular \\ de sociologia da \\ Universidade do \\ Estado do Rio de \\ Janeiro (Uerj). \\ Doutora em \\ sociologia pelo luperj \\ (1991), bolsista \\ produtividade \\ CNPq, autora, entre \\ outros, de Tempos de \\ Capanema (coautoria \\ com Simon \\ Schwartzman e \\ Vanda Maria Ribeiro \\ Costa), Guardiães \\ da razão, Darcy \\ Ribeiro: sociologia \\ de um indisciplinado \\ e Um poeta na \\ política: Mário de \\ Andrade, paixão \\ e compromisso. \\ <helena.bomeny@ \\ hotmail.com>.
}




\section{Antecedentes:}

\section{o sonho de reparação}

Inventar uma capital no Planalto Central do Brasil foi daquelas aventuras avassaladoras que se transbordaram em muitas fontes e frentes de divulgação. Foi desses feitos badalados pela crítica, por entusiastas do projeto, pelos profissionais que se envolveram no empreendimento, e pelos intelectuais que deram tratos à bola para explicar e conferir certa racionalidade ao gigantesco movimento de construção de uma cidade no espaço de terra vermelha, isolado, desprovido de atração. Não faltaram justificativas: unificar o país, criar um elo a partir do centro para as demais regiões do território nacional, irradiar pelo novo espaço valores sociais, políticos e estéticos capazes de traduzir a cultura brasileira em seus múltiplos aspectos. E, sobretudo, escapar dos vícios já arraigados da antiga capital litorânea - Rio de Janeiro. O discurso foi construído com a força argumentativa de algo que se edifica do zero, e sustentado na suposição da capacidade e da potência da razão em modelar um novo Brasil. Tudo isso foi ungido em atmosfera onde se projetariam arquitetos artífices dos ideais de modernidade e beleza a presidirem a engenhosidade humana.

Brasília, que começou a ser construída no ano de 1956, veio de processo anterior e de investidas mais ou menos consequentes, protagonizadas por um espectro amplo de profissionais e políticos. Data deste período, entre 1957 e 1958, a luta pela criação da Universidade de Brasília (UnB). A ideia de criação de uma universidade na nova capital do país justificava-se pelo argumento de que o centro do poder deveria ter no plano cultural o equivalente ao que era exibido no plano arquitetônico ou urbanístico. A universidade corresponderia ao desafio inovador que a cidade de Brasília representava no cenário urbano brasileiro. O antropólogo Darcy Ribeiro (1922-1997) esteve envolvido à exaustão nessa fase inicial de construção do que, em sua perspectiva, confirmaria o ineditismo da nova capital: a criação de uma universidade modelo, à frente de seu tempo, inovadora, sintonizada com os ares de refundação do país.

Só uma universidade capaz de expressar a nacionalidade - proclamava o antropólogo - podia conseguir que a nova capital não se acanhasse diante de São Paulo e de outras metrópoles brasileiras. Ela teria condições, dadas as peculiaridades de sua organização, de se replicar em "novas Brasílias" de igual ousadia e correspondente qualidade, vocalizava Darcy Ribeiro. A criação da universidade, a despeito de uma ou outra voz dissonante, esteve e está associada à liderança de Darcy, o antropólogo que percorreu os espaços políticos na busca obsessiva de tirar o Brasil do atraso, da imobilidade, da dependência a marcos de referência externos, do rompimento com 
a subalternidade na recusa a modelos exógenos conclamados para traduzir a cultura brasileira. Conhecido por fortes traços de personalidade, pela impetuosidade, paixão e fervor inventivo, Darcy é lembrado também pela impaciência, resistência e desobediência (com tudo o que sociologicamente significa) aos trâmites rotineiros de que se fazem os processos institucionais. Arroubos criativos enfrentavam os degraus da implantação com resultados nem sempre correspondentes ao estímulo original. O projeto de criação da universidade, aposta que fez a propósito da UnB, foi um dos seus mais cultivados impulsos de interferência na ordem pública pela cultura. Reinariam naquele ambiente universitário a cultura, a ciência e os experimentos de invenção democráticos.

Apostava-se que a universidade fosse capaz de assessorar o governo no plano científico humanístico. Afinal, tratava-se da nova capital, o espaço do poder. A universidade poderia levar para a capital a massa crítica necessária para cobrir todos os campos do saber. Para tanto, havia de ser livre, não sofrer punição nem premiação por suas ideias. Mais importante: havia de atrair os cérebros criativos e bem-dotados em áreas de atuação indispensáveis a uma universidade de excelência. Habitava ainda a atmosfera de criação da universidade a aspiração de que a instituição não fosse conivente com a ordem. A metáfora mobilizada era de "universidade útero", dentro do qual se reproduzissem lideranças e competências em amplo espectro do conhecimento. No entanto, como um dos autores do projeto, Darcy Ribeiro alimentava sua tradicional desconfiança em relação à receptividade por parte da elite de empreendimento movido por tal ousadia. O projeto estava inserido em um país e era tributário de uma cultura política - insistia ele - onde a classe dominante desprezara historicamente a educação, além de ter se empenhado mediocremente em saúde e em todas as dimensões de aprimoramento da vida da população. Mas os idealizadores não podiam sucumbir diante da desconfiança; ao contrário, teriam de empunhar a bandeira de uma universidade estruturada de forma a representar a consciência crítica, o que só seria possível no interior de uma ordem democrática.

A UnB seria o centro de florescimento cultural, de criatividade nas letras e nas artes: o espaço privilegiado para a realização dos projetos de sensibilidade e cultura. Compareceram naquele ambiente cineastas, artistas plásticos, designers, arquitetos, poetas, escritores e atores, recriando, para um conjunto de recém-chegados à capital, oportunidades de conhecimento, formação e fruição de cultura em sua dimensão mais plural.

Na avaliação de Darcy Ribeiro, o Brasil já dera demonstrações de certas competências: formar médicos, físicos, químicos, farmacêuticos, matemáticos, antropólogos etc. Mas fazer outro Oscar Niemeyer, outro Cândido Portinari, outro Aleijadinho, era totalmente impossível. Não há replicação espontânea ou voluntária desse fenôme- 
no, pontificava. Se não é possível saber como promover o florescimento cultural e a emergência de talentos de grande expressão, era possível criar um ambiente de liberdade de convivência no campus universitário em Brasília para que "surgissem figuras criativas, coatadas, que pudessem se expressar". Por tudo isso, a UnB, quando convocada como plano, configurou-se como utopia concreta - a universidade ideal a que se queria chegar, uma universidade que "pedia silêncio", na expressão de Darcy, para ser a melhor do mundo, uma universidade autônoma, dona de si mesma e libertária no sentido de dar ao país um instrumento de autonomia no seu desenvolvimento cultural. A desconfiança de Darcy Ribeiro reforça o primado da imposição do social, da estrutura sobre possibilidades de autonomia e desenvolvimento dos atores, dilema clássico da teoria social. Sua trajetória como intelectual público engajado politicamente é permeada de gestos, ações e deliberações que reforçam sua descrença na capacidade de, no ambiente de institucionalização, florescerem e serem cultivadas e mantidas propostas renovadoras provenientes da imaginação dos atores.

É possível dizer que a Universidade de Brasília, criada pela Lei n. 3.998, de 15 de dezembro de 1961, nasceu de um sonho e de um propósito de reparação. Um sonho de reparação ao destino que fora dado à Universidade do Distrito Federal (UDF), no Rio de Janeiro, então capital do Brasil. Universidade de curta duração (1935-1939), mas de forte repercussão. Forte como projeto, efêmera pela intervenção autoritária. Vinte e tantos anos depois, ressurgiria com a UnB o modelo universitário pensado para o desenvolvimento da ciência e da cultura em ambiente de efervescência, criatividade e troca intelectual, inspirado no modelo que não vingou na antiga capital. A Universidade do Distrito Federal (UDF), apesar de sua vida bruscamente interrompida aos quatro anos de existência, deixara como memória institucional o que seria desejável manter na vida universitária em fundação. Os atores comprometidos com a universidade de Brasília foram protagonistas em ambas as iniciativas, e por isso, o cruzamento de sonho com reparação. Em julho de 1935, o educador Anísio Teixeira (1900-1971) se transformava em figura exponencial na montagem de um projeto universitário que se distinguia na forma pela qual conhecimento e interação institucional se materializariam. À época, Anísio ocupava o cargo de diretor do Departamento de Educação do Rio de Janeiro, capital federal do país. A Universidade de São Paulo (USP), criada em 1934, era o modelo disponível. O desenho de universidade defendido para a UDF pretendia que os professores fossem profissionais ativos, criadores. Esta era a aposta registrada pelo físico Roberto Salmeron:

Efetivamente, os professores eram eminentes cientistas que trabalhavam em instituições existentes no Rio de Janeiro em ciências 
humanas e ciências naturais e exatas, além de eminentes artistas. Para citar alguns exemplos, Mário de Andrade lecionava história e filosofia da arte; Cândido Portinari ensinava pintura; Villa-Lobos, música; Jorge de Lima, Gilberto Freyre, Artur Ramos, Hermes Lima, Sérgio Buarque de Holanda, ensinavam ciências humanas (Salmeron, 2005).

Sem qualquer indício de monumentalidade, a Universidade do Distrito Federal se mantinha com orçamento limitado, não se destacava por prédios majestosos. As aulas eram ministradas nos lugares de trabalho dos professores. Mantidos em seus espaços institucionais de origem, os professores recebiam da UDF um complemento para a atividade ali realizada. A despeito de tal singeleza, ficou intolerável para o regime autoritário. Com o golpe de 1937, viveu seu momento de perseguição até ser extinta por meio de artimanhas administrativas e um decreto federal em 1939. "Manter a disciplina e a ordem" - esta foi a sentença que fixou o ato discricionário. O "perigo vermelho" - expressão cunhada por Rodrigo Patto Sá Motta (2002) - teria, já ali, peso de legitimação do que se enterrava antes ainda da maturação. As tintas liberais que a modelaram foram transformadas em ameaças desestabilizadoras ao regime autoritário.

Não é momento de tratar da UDF, mas sua menção é requisitada pela maneira como a liderança envolvida na criação da Universidade de Brasília a ela se refere e dela se apropriou em nota positiva de um experimento singular, inspirador, à feição do que a USP iniciara em 1934, indicativa de uma brisa nova na estrutura do ensino superior brasileiro no momento de sua fecundação. A UDF foi abortada pela ação autoritária do regime político quando estava à frente do Ministério da Educação aquele que assinou o ato de sua extinção: Gustavo Capanema (1900-1985).

\section{Tempo I:}

a utopia de nação invade a universidade

A revista Arte Hoje, em sua edição de 22 de abril de 1979, traz em beleza incomum, as fotos de Luís Humberto, fotógrafo que elegeu Brasília sua cidade de adoção. Luís Humberto foi homenageado e reconhecido como aquele que mais sofisticadamente captou a atmosfera daquela invenção urbana, aquele que, pelos olhos, nos leva a desvendar o enigma de uma cidade cuja monumentalidade constrói - palavras do fotógrafo - "uma relação entre o homem e os espaços da cidade, pensados em termos de liberdade".

Luís Humberto mostra a Brasília não óbvia. Aquela que só olhos treinados podem descortinar. Sensibilidade e pesquisa são suas parceiras na descoberta. Um canto, 
um prisma, um tipo de luz e encontramos o que não está disponível de imediato. O olho nu e a intuição não são suficientes para nos abrir essa janela. As imagens produzidas pelo fotógrafo foram a porta de entrada para o que se traduziu como capital estética do modernismo em sua plenitude. Como os olhos especializados do fotógrafo, outros olhos, também especializados, foram buscar as origens e os ensaios de construção da nova capital muito antes da velocidade com que ficou registrada na memória dos "cinquenta anos em cinco" dos tempos de JK. Brasília é capital do modernismo. Da monumentalidade. Da internacionalização da arquitetura brasileira na concepção de Lúcio Costa e nos traços de Oscar Niemeyer. Cidade sem esquina, espaços vazios, generosa amplitude na concepção urbana, dimensões não características do figurino das cidades brasileiras. E é também o experimento cultural capaz de emocionar aqueles que lá estiveram em sua construção.

A discussão sobre a mudança da capital mobilizou um conjunto de sugestões interpretativas sobre o Brasil. O tema da "desorganização", a defesa da interiorização, o diagnóstico da dispersão nacional junto à retórica antifederalista que se vertebrou no pós-1930 transformaram negativamente o período anterior, nomeando-o "República Velha" - período compreendido entre 1889 e 1930. A adjetivação "velha" como que autorizou as expressões negativas que se seguiram: "República dos coronéis", do "mandonismo local", perfilando a dimensão de inorganicidade que o pós30 atribuiu ao período que the antecedeu. A montagem do Estado nacional racionalizado, técnico e administrado segundo as regras impessoais do planejamento e da competência científica se contrapunha como correção histórica ao experimento anterior. Recentemente, historiadores e cientistas sociais têm se voltado ao período referindo-se a ele como Primeira República, um claro afastamento crítico à adjetivada República "Velha". A própria terminologia "Revolução de 30" é expressivo do sentido de ruptura que se pretendeu imprimir à passagem de um a outro momento histórico-político brasileiro tematizado e mobilizado como reforço discursivo à defesa do ponto central de onde deveria irradiar a política e a administração brasileiras.

A extensão continental e a precária integração entre litoral e interior desafiaram a imaginação política e geográfica, e as expedições tratavam de enfrentar o problema e registrar o encontrado. O tema da mudança da capital para o Planalto estava posto praticamente no início do século XIX, com a vinda da família real. E a defesa do centro encontrava apoio em aspectos da geografia natural. Aos argumentos de ligação territorial somavam-se outros sobre a impropriedade do ambiente do litoral de uma cidade como o Rio de Janeiro para abrigar a capital do país - conversa antiga, perene, que acompanha a história da cidade do Rio de Janeiro, paraíso da espontaneidade, da informalidade e do cosmopolitismo; fonte da liberdade e criatividade, mas também da perversão e da luxúria. Não bastasse, o Rio do início da 
República era a cidade das doenças, da insalubridade, da peste, do clima inclemente e da desordem urbana.

A construção de Brasília foi tomada, simbolicamente, de um sentido de refundação. Uma utopia de reconstrução nacional que aparece nos documentos, nas falas dos que estiveram naquele que foi cantado em prosa e verso como o canteiro de obras, ou, na expressão feliz de Angélica Madeira, "espaço quase em branco, sem referência cultural prévia" (Madeira, 2013).

Mobilizou-se uma caravana de geógrafos, engenheiros, estatísticos, intelectuais, fotógrafos, arquitetos, artistas, cineastas, empreendedores de toda ordem, no desafio de, em cinco anos, fazer de um terreno vazio uma cidade. A oportunidade histórica incomum de fazer tudo "do zero" era como uma reinvenção do país; oportunidade de reescrever a história e deixar para trás o que impedia o Brasil de avançar em um cotidiano de travas. Livrava-se o país das tradições que o emperravam. Dispensavam-se os embaraços burocráticos. Avançava-se apenas com a imaginação e o empenho em fazer. Os relatos que colhi em 2005 com um grupo de arquitetos, e com o próprio Luís Humberto, são evidências inequívocas das lembranças desse espírito inventivo, protagonista, liberto e criativo. A construção da capital supunha a mobilização da cultura, das artes plásticas, da arquitetura, das artes cênicas, da música. A defesa da criação da universidade ancorava-se no argumento irrecusável de abrigar as múltiplas manifestações de humanidade traduzidas na diversidade de expressão artística. A urbs estava criada; a civita seria tributária do ambiente da universidade pensada e construída sob esta ambição. A aura da construção da Universidade de Brasília, nas inúmeras frases de Darcy Ribeiro, confirma o clima otimista e desafiador da nova experiência liberta das amarras do tradicionalismo e da burocracia que tolhem os espíritos e acanham a cultura. Os depoimentos apaixonados de Darcy fazem coro com as vozes otimistas dos que presenciaram o experimento único e não reproduzível.

Das entrevistas realizadas com os arquitetos foi possível recuperar falas que expressavam a "emoção de viver sob maquetes" anunciando tudo o que representava a construção do real modelado por planos que poderiam ser alterados pelos atores. Nada estava fechado; tudo por fazer; espaço de inconteste liberdade e criatividade. A mais consequente aposta na razão criativa, emancipatória. A metáfora de o Brasil sair "dos puxadinhos" e entrar em maquetes estruturantes fortalecia a ideia de refundação da nação. Esta é uma ideia curiosa e interessante. O que significa sair dos puxadinhos? Significa para os arquitetos interromper um processo continuado de emendas, remendos, ampliações que esticam uma construção anterior mesmo sem garantia de guardar fidelidade ao que seria o desenho original. Mas significa 
igualmente evitar o conhecido, o já posto. Espécie de negação do anteriormente estabelecido e aposta naquilo que nascerá do controle da razão. Não deixa de ser uma indicação de "liberdade planejada" com régua e compasso. A caravana de arquitetos que saiu do Rio de Janeiro rumo ao Planalto Central foi embalada no clima da saída do marasmo que assolava o Rio de Janeiro do ponto de vista da arquitetura. Começar do zero significava a oportunidade única e extraordinária de evitar os erros, corrigir as mazelas e os vícios convencionais, e de deixar sua marca autoral. Uma fé extraordinária na capacidade de imaginação sobre um espaço aberto à produção e ao aperfeiçoamento porque a aventura reconstrutora estava sob o comando de homens e mulheres racionais capazes de evitar os embaraços rotineiros que impediam o Brasil de chegar ao seu destino de civilização. A força desse sentimento coletivo tem sido uma marca da recuperação do período: expressões e categorias de análise têm ocupado a avaliação dos anos 1960: "romantismo revolucionário"; "estrutura de sentimentos" de brasilidade (Marcelo Ridenti); "ideias que fazem o Estado andar" (João Marcelo Maia); "sentido público e coletivo da atividade intelectual” (Maria Alice Rezende, Gildo Marçal); "intelectuais e espaço público" (Francisco de Oliveira), intelectuais orgânicos incubadores de projetos de nacionalidade, sentido uníssono de adesão coletiva a uma ideia (Thomaz Farkas), tudo isso atravessa a literatura sobre intelectuais no Brasil, sendo nela uma constante o não rotineiro dos anos 1960. O cineasta Thomaz Farkas fortalece o coro de certa unanimidade nas lembranças: "O que nos unia era um pensamento muito parecido". O parecido era o som uníssono de mudar o Brasil, mostrar o Brasil aos brasileiros, trazer para a consciência da população o que a própria população desconhecia. Um ideal de nação que se ligava fortemente à ideia de transformação que seria disseminada não apenas pelos técnicos, mas se embrenharia nas manifestações mais distintas da imaginação política e criativa: a fotografia, o cinema, o teatro, a literatura, a música. Dar consciência era tão revolucionário quanto uma revolução, conclui o cineasta. A cidade - ela própria fruto da imaginação política e do desenho utópico de perfeição - ancorava o projeto transformador e se magnificava como centro do poder refundador da estética e da cultura nacionais.

Não apenas os arquitetos justificaram a capital da cultura. No livro de Angélica Madeira (2013), a autora reconstrói, passo a passo, a trajetória e a itinerância dos artistas na construção do campo das artes visuais da nova capital. Percorre o período entre 1958 e 2008 e oferece ao leitor um quadro detalhado do que fora aquele momento de invenção do Brasil pela construção da nova capital. Os monumentos, os espaços públicos, os prédios que abrigaram não só os ministérios, mas o Congresso Nacional, o Palácio do Governo, o Palácio da Justiça, o Palácio do Itamaraty, e a própria universidade construída na ocasião, receberam o selo, a assinatura e as obras de artistas consagrados no repertório da cultura modernista brasileira. A primeira 
leva de artistas que chega à cidade, no final dos anos 1950, alguns vinculados a Oscar Niemeyer e a sua equipe, outros independentes, teve como mecenas principal o Estado, e deixou na nova capital os ingredientes necessários para a construção de uma memória de cidade capital, símbolo da cultura e da civilização ambicionadas. Angélica Madeira nos lembra da atmosfera dos anos 1950 para as artes plásticas, fomentadas pela criação da Bienal de São Paulo e a consolidação de recentes museus, em São Paulo e no Rio de Janeiro. A fisionomia estética da cidade foi marcada por artistas como Athos Bulcão (1918-2008).

\begin{abstract}
Athos envolve-se profundamente com o projeto da cidade, realizando obras que o definiram como um grande modelador da face pública de Brasília, inventor de um muralismo geométrico, original e renovado. Em Brasília também consagrou-se como artista intimista, como pintor e gravador (Madeira, 2013, 37).
\end{abstract}

A ideia de que a arquitetura brasileira havia levado o país para os grandes centros internacionais fica fortalecida com a presença dos artistas plásticos que assinaram obras expostas em fóruns internacionais como Lisboa, Madri, Milão, Munique, Tóquio em exposições onde croquis, desenhos, fotografias das obras de Brasília ocuparam a cena principal. Entre os espaços de divulgação dos feitos ali postos há que se dar relevo à crítica de arte, e ao papel fulcral que nela desempenhou a atuação de Mário Pedrosa (1900-1981) (Villas Bôas, 2013; Moura,2014). Esses lembretes são apenas aperitivos para se dimensionar a importância do que foi se consolidando como o momento do moderno brasileiro em sua expressão mais aguda e sua repercussão mais concentrada. O que dá razão ao comentário de Madeira quando nos diz que

\begin{abstract}
a inauguração da Nova Capital, em 21 de abril de 1960, ficou marcada na história brasileira como um emblema da modernização do país e da ousadia da proposta de interiorização, industrialização e integração encampadas pelo governo JK. Foi um marco também para mensurar a força e a energia da sociedade, seu envolvimento nesse projeto utópico. Desenhada, exata e racional, a cidade destaca-se, antes de mais nada, por sua concepção ortogonal, horizontalizada, delimitando com precisão a linha que separa a natureza da civilização, o cerrado da urbs. A sensibilidade moderna dos anos 1950 estabeleceu Brasília como o parâmetro de sua própria utopia (Madeira, 2013: 38).
\end{abstract}

A atmosfera de excepcionalidade não se restringiu aos que, em amplo sentido, protagonizaram o invento. A fala transbordou para jovens que viveram na incipiente cidade capital daquele momento, quer na condição de estudante secundarista, como o cientista político Sérgio Abranches, quer na posição de estudante universitária, 
1. Entrevistas concedidas por Sérgio Abranches e Mariza Peirano a Helena Bomeny em 2004 e 2005, respectivamente. como a antropóloga Mariza Peirano, arquitetura em formação no momento original da UnB. Os depoimentos de ambos reforçam a ideia de um clima especial onde se integrava na universidade um número de atividades e, particularmente, um tipo de interação entre professores, estudantes, instituições de ensino médio e universitário em nada comparável ao que se observou depois na própria UnB e o que se observa hoje em nossa estrutura de ensino superior ${ }^{1}$.

A energia que tomava conta dos que se empolgavam com o projeto da nova capital espraiava para a universidade. Como se sabe, a universidade não foi incluída de imediato no projeto JK de reinvenção do Brasil. Os mineiros, na figura de Israel Pinheiro, engenheiro e construtor de Brasília, distante do projeto intelectual ali envolvido, temiam pelo que pudesse acontecer. Afinal, seriam incontroláveis os efeitos da vida associativa das organizações estudantis, da mobilização das associações organizadas, representando riscos de instabilidade da ordem estabelecida. Imagine-se o que seria da capital com operários fazendo greves e estudantes promovendo passeatas! Argumentos dessa natureza alteravam até mesmo planos urbanísticos de Lúcio Costa, quando as sugestões de espaço reservado para o campus eram vetadas.

Com a eleição de Juscelino Kubitschek, em 1955, Darcy é convidado a colaborar na elaboração das diretrizes para o setor educacional do novo governo. Trabalhou em conjunto com Anísio Teixeira. Darcy chega a mencionar que foi uma luta convencer as autoridades de que seria incabível uma cidade construída sob parâmetros tão modernos, ousada e inovadora, com pretensões de estar associada ao futuro, não receber em seu ambiente a criação da universidade como um centro de qualificação que ficasse à altura da ousadia arquitetônica que exibia. No livro Por que construí Brasília, JK (1998) reserva um capítulo à universidade da nova capital, mas, como bem observou Salmeron, causa estranheza o fato de um capítulo de 18 páginas com esse título ter de fato tratado da universidade em quatro parágrafos. Neles, o presidente justifica a ausência da iniciativa no momento da construção de Brasília: tão ambiciosa era a ideia de construção de uma universidade, ou melhor, de uma Cidade Universitária, capaz de converter Brasília num foco de cultura dos mais lúcidos e sensíveis do país, que a

Universidade de Brasília não poderia ser concebida antes que a cidade atingisse certo estágio de construção - o de seu acabamento (Salmeron, 1999: 43).

Uma estratégia eficaz de convencimento foi tocar na vaidade de um governante que pretendia passar à história como aquele que faria cinquenta anos em cinco em clima de liberdade democrática; que levaria o país ao banquete da civilização pela liberdade. Como era possível - replicava Darcy Ribeiro - que um projeto de cidade 
de tal envergadura deixasse fora a universidade? Não ficava bem para uma grande liderança, como a que JK encarnava. Problemas foram contornados, o campus afinal acabou sendo levado para um espaço a sete quilômetros de Brasília.

Ao lado da resistência original, outra Ihe concorria com igual vigor. A Igreja católica disputava o espaço com a proposta feita por Don Helder Câmara de criação de uma universidade católica sob o argumento de que, na capital norte-americana, a mais importante universidade era católica. JK, mineiramente, não se opôs. Ao contrário, "lavou as mãos", registra Darcy Ribeiro. Mais um obstáculo ao projeto original que seria vencido pela negociação. A Universidade de Brasília seria construída como pública e laica, mas abrigaria em seu campus o Instituto de Teologia Católica. No documento onde Darcy Ribeiro relata o episódio, recuperamos o argumento: levou-se ao papa João XXIII a informação de que oito universidades católicas funcionavam no Brasil, todas formando dentistas, médicos, engenheiros, farmacêuticos, sendo que, em nenhuma delas havia espaço designado à formação teológica. A UnB poderia receber qualquer sacerdote com formação básica e seriam dados a esse sacerdote os complementos de estudo para ter mestrado em teologia e doutorado em teodiceia. Receberam o sinal verde de sua santidade, com o que, finalmente, o projeto da UnB poderia ser encaminhado à votação no Congresso Nacional, no tardio dia da inauguração da nova capital... Contara para o sucesso, ainda segundo nosso interlocutor, o braço dominicano na figura do frei Mateus Rocha, o mensageiro que foi a Roma procurar o santo padre João XXIII, em companhia do geral dos dominicanos - o chamado papa branco - a quem teria feito a entrega da proposta assinada por Darcy Ribeiro. Sem qualquer documento escrito, a Igreja declinou do projeto original e consentiu na sugestão do Instituto de Teologia Católica dentro da Universidade².

Outro momento de grande expectativa registrado na documentação por Darcy Ribeiro foi o dia da renúncia do então presidente Jânio Quadros, em agosto de 1961. O projeto da Universidade de Brasília estava em pauta para votação; o Congresso em convulsão. Darcy descreve com detalhes as manobras que tentou junto aos políticos para incluir como primeiro ponto de pauta a aprovação do projeto de criação da universidade. Perplexos, no primeiro momento, convencidos, em seguida, possivelmente até por incertezas sobre o curso parlamentar em tal conjuntura, a UnB recebeu a votação suficiente para partir para regulamentação, o que já ocorreu no governo João Goulart, vice-presidente eleito na chapa de oposição a Jânio Quadros, que presidiu o país em sucessão a JK. Com a renúncia de Jânio, em agosto de 1961, e em meio a uma crise político militar, João Goulart assume a presidência como previa a Constituição, em setembro de 1961. Da Câmara ao Senado, as negociações pela aprovação do projeto da UnB prosseguiram. A sugestão do então primeiro-ministro, Hermes de Lima, com quem Darcy se aconselhou a respeito
2. É de Darcy Ribeiro o comentário: "Quando da decisão de fazer o Instituto de Teologia, frei Mateus acabou sendo vice-reitor da UnB. Nesta ocasião, vários colegas se rebelaram contra mim com a ideia de que eu fazia uma concessão tremenda, que era inaceitável no plano ideológico e houve até quem dissesse que aquela era uma atitude oportunista e talvez até fosse..." (Ribeiro, 1978). 
3. O que se seguiu foi o tumulto de uma câmara que demorou alguns minutos a perceber do que se tratava, que era fazê-los exercer suas funções, discutindo uma lei de suprema importância. Os debates foram acalorados entre a UDN, como sempre contrária aos projetos do governo, e os outros partidos, com o pendor de aprová-lo. O mais veemente discurso contrário foi o do velho Raul Pilla, ponderando que, se nossos pais e avós mandavam seus filhos estudarem em Coimbra, bem poderia o povo de Brasília mandar os seus para as antigas universidades. Sem incorrer no risco de criar aventureiramente uma universidade em uma cidade apenas nascente. $\mathrm{Na}$ votação, o projeto da Universidade de Brasília foi aprovado com 154 votos a favor e 50 contra (Ribeiro, 1959).

\section{A discussão} sobre a criação da universidade de Brasília se cruzava com um movimento que ganhava força na comunidade científica pela reforma universitária no Brasil. Uma das iniciativas veio da SBPC em uma reunião especial no Rio de Janeiro, em outubro de 1960. Os intelectuais presentes nesta reunião em boa medida se da melhor estratégia de convencimento junto aos senadores, foi que procurasse Filinto Müller. "Tratava-se de aproximar dois extremos simbólicos - o meu de esquerdista e o de Filinto, direitista" - registra Darcy. "Não se inquieta, professor. O problema agora é meu. Breve eu the farei saber quando será a discussão final em plenário" - teria respondido Filinto, na lembrança recuperada por Darcy. Também ali, o projeto foi aprovado por imensa maioria, a despeito do discurso do senador Mem de Sá que chamava a atenção para a competência, a inteligência e a coerência de Darcy Ribeiro, mas também sua afinidade com a esquerda e um reconhecido comunista. A universidade - alertava o senador - seria uma universidade comunista. Finalmente, depois de três anos de negociações e controvérsias, foi aprovada a criação da universidade em dezembro de $1961^{3}$. Aprovava-se afinal a universidade pública, laica e gratuita, como rezava a cartilha dos pioneiros da educação nova transposta para a invenção do ensino superior, em troca da criação, no interior da universidade, de um instituto de teologia. Convencido do acerto do projeto, o presidente autorizou sua realização. Naquele momento, extravasou para o clima de construção do projeto universitário a atmosfera do "partir do zero", no sentido da invenção, tal como representava para a nação, o "partir do zero" da construção da nova capital, parteira de novo país. Darcy Ribeiro seria o primeiro reitor, e Anísio Teixeira, o vice-reitor.

O espírito inovador traduziria a experiência da universidade. O tom dos missivistas (matemáticos, físicos, cientistas sociais brasileiros e norte-americanos, cineastas e fotógrafos) é de esperança e entusiasmo ${ }^{4}$. Em carta datada de 1960, Agostinho da Silva dá mostras do espírito que presidia a receptividade da fundação daquela universidade. Embrenharam-se na universidade com a força de quem olha para algo por se construir: "as maquetes intelectuais" construídas nos artifícios da colaboração. Poderia ser um centro de nucleação cultural, estimuladora e nova diante de estruturas tão obsoletas do ensino superior vigentes no período anterior à Reforma de 1968. A receita era clara: esperança de, finalmente, rompendo as amarras de uma tradição inerte e viciada, construir algo novo, fora da burocracia, flexível, criativa, imaginativa. Sobre uma folha em branco, o traçado da imaginação. Uma ambição ampla: a universidade funcionaria como um centro de cultura que teria influência e interlocução com a América Latina e com ex-colônias africanas em processo de independência.

Não esqueça - escrevia Agostinho da Silva a Darcy - que provavelmente Portugal não aguentará muitos anos as atuais províncias ultramarinas e que a presença cultural do Brasil vai ser nesses pontos de fundamental importância; para os territórios e para as áreas vizinhas: África sudanesa e banta, Índia, Indonésia e China. O momento de coordenar e preparar tudo isso é agora, e acho até 
que antes de findar esse período governativo: seria, parece-me, uma excelente forma de lançar as atividades culturais de Brasília (Silva, 1960).

Antes da Reforma Universitária de 1968, a UnB já abandonara o regime de cátedra que vigia em todo ensino superior brasileiro. $\mathrm{O}$ ar de renovação impregnava toda aquela geração convocada por Darcy Ribeiro de forma apaixonada, errática e bastante informal, no "largue tudo e venha realizar seu sonho", como matemático, físico, cineasta, artista, fotógrafo, designer, cientista social, arquiteto, linguista etc. "Se você tem um sonho, esta é a hora de apostar. Venha! E foram" - assim se expressou o matemático Elon Lajes em entrevista concedida à autora. Afinal, não era pouco: tratava-se de uma universidade participante do próprio projeto de nação, integrada nas grandes questões nacionais e, ao mesmo tempo, referência de conhecimento, inovação, criatividade, flexibilidade.

Um ano depois de criada, a UnB abria cursos em base transitória para que, posteriormente, fossem absorvidos pelos Institutos Centrais. Cursos considerados de alto padrão em direito, administração pública, economia, arquitetura e urbanismo e letras brasileiras. O destaque vinha com os cursos de pós-graduação, procurados por estudantes brasileiros e estrangeiros abrigados nas residências para alunos e professores que vinham de outros estados ou outros países. Ampliava-se assim a convocação em escala internacional com alunos de países como a Checoslováquia e o México, atraídos pelos cursos de pós-graduação em arquitetura e urbanismo, estimulados pela possibilidade de estágio no escritório de Oscar Niemeyer.

A UnB começou a funcionar no dia 9 abril de 1962, graças a Anísio Teixeira, que conseguiu duas coisas importantes: salas emprestadas pelo Ministério da Educação e verbas de emergência. Os primeiros cursos da foram reunidos em três grupos chamados "cursos troncos": letras brasileiras, coordenado por Cyro dos Anjos, que deu origem ao futuro Instituto Central de Letras; administração, direito e economia, coordenado por Victor Nunes Leal, gérmen do Instituto Central de Ciências Humanas; arquitetura e urbanismo, iniciado por Alcides da Rocha Miranda, posteriormente dividido em Faculdade de Arquitetura e Urbanismo, coordenada por Oscar Niemeyer, e Instituto Central de Artes, coordenado pelo próprio Rocha Miranda.

As aulas eram dadas no Ministério da Educação. Os primeiros cursos ministrados no campus da Universidade foram os de arquitetura, no pequeno e modesto edifício de madeira carinhosamente chamado "Oca", construído por Sérgio Rodrigues, edifício que ainda existe e que se reclama seja conservado como monumento histórico da Universidade de Brasília. envolveram também na implantação da Universidade de Brasília, indicando a sintonia da criação de uma universidade com uma atmosfera crítica a respeito do modelo existente no país. Estiveram na reunião os físicos Gleb Wataghin, José Leite Lopes, Mário Schembert, José Goldemberg, Jayme Tiomno, Richard Wallauschek, Oscar Sala, Guido Beck, Lauro Nepomuceno; os matemáticos Leopoldo Nachbin, Maria Laura Leite Lopes, A. Pereira Gomes; os químicos J. Cristóvão

Cardoso, Jacques Danon, Walter B. Mors, Júlio Pudles, Ricardo Ferreira, Lúcia Furtado; os geógrafos Orlando Valverde, Pinchas Geiger, Fábio M.

S. Guimarães, o diplomata Wladimir Murtinho; o filósofo Euryalo Cannabrava; os biólogos Paulo Sawaya, F. Briguer, Carlos Chagas F., W. Oswaldo Cruz, Haiti Moussatché M. Rocha e Silva, Crodovaldo Pavan, Newton F. Maia, J. Ribeiro do Valle, S. Baeta Henriques, Annie P. Danon, Amadeu Cury, Herman Lent, Antonio Couceiro O. Frota Pessoa, Segadas Viana, Carlos Zilberstchmidt; os médicos Arthur Moses, Paulo de Góes, M. de Freitas Amorim, Haydée G. Dourado; os escritores Cyro dos Anjos, Paulo Duarte, Afrânio Coutinho, 
J. I. Mendonça, P. Madureira de Pinho; os historiadores Maria Yedda Leite Linhares, Francisco Iglésias; o crítico de arte Mário Pedrosa; os antropólogos Darcy Ribeiro, Carlos de Araújo Moreira Neto, Roberto Cardoso de Oliveira, Josidelth

G. Consorte; os economistas Celso Furtado, Pompeu Acioly Borges, Ignácio Rangel; os educadores Anísio Teixeira, Almir de Castro, Jayme Abreu, Faria Goes Sobrinho, Alberto Venâncio Filho; o sociólogo Florestan Fernandes.

\section{Argumento} paralelo ao de outra invenção, igualmente mineira, quando da construção de Belo Horizonte no final do século XIX. A cidade planejada cartesianamente com régua e compasso viria substituir a barroca e sinuosa Ouro Preto, levando a modernidade e a racionalidade ao estado de Minas Gerais (Bomeny, 1994b).
A avaliação de Darcy Ribeiro sobre a excepcionalidade do projeto de universidade implantado na capital da República repousava ainda na forma como fora construído. Da Sociedade Brasileira para o Progresso da Ciência (SBPC) a um conjunto significativo de intelectuais oriundos dos diversos campos do saber, a UnB recebia apoio para sua fundação na aposta de que se tratava de uma instituição que não era cópia de qualquer padrão estrangeiro, mas provinha do esforço concreto de repensar radicalmente a universidade. Desde as bases, ela deveria ser uma "universidade instrumento", diferente, nas palavras de Darcy, da "universidade fruto".

A construção da memória tem suas particularidades. E tem seus defeitos. Conta com artifícios estratégicos de seleção, inclusão, valorização, mas também, e muito fortemente, de omissão. Não chamar a atenção para uma ou outra dimensão é parte desse processo que, aprendemos com a literatura, nada tem de natural. Memória não é história, embora seja, indiscutivelmente, uma das dimensões incorporadas no trabalho historiográfico. Daí a importância de um livro como Veredas de Brasília (Senra, 2010) composto por um conjunto de capítulos escritos com o objetivo de percorrer o trajeto da discussão sobre a mudança da capital, bastante anterior à data fixada no governo JK. Na abertura, Nísia Trindade Lima recupera todo o debate secular a respeito da conveniência de levar o país ao interior. A análise dos projetos, os dispositivos constitucionais e os estudos cuja origem - nos lembra ela - remonta ao século XVIII estão ali perfilados. A tramitação das comissões e a atuação dos envolvidos na discussão sobre a mudança da capital, os interlocutores e as sugestões possíveis de local sustentam os demais textos desenhados a partir de recortes mais específicos. Uma reflexão sobre os impasses e obstáculos à construção de um país dividido entre litoral e sertão, divisão mais que geográfica, política, social, econômica e cultural (Lima, 1999).

Em todas as expedições, a reiteração da tese da necessidade de se encontrar o ponto ótimo a partir do qual a integração nacional fosse efetivada. A desafiar os atores a geopolítica na construção de um ideário de comunicação nacional, de construção do ideal de nação ligada em toda sua extensão continental ${ }^{5}$.

O Instituto Brasileiro de Geografia e Estatística (IBGE) proporcionou a realização de expedições, estudos, debates e produção de dados sobre possibilidades e riscos de opções concorrentes à eleição do espaço para a nova capital. O discurso político em torno da mudança da capital e do esforço monumental de uma produção de tal envergadura em cinco anos consagrou no senso comum a ideia de um fazer "a partir do zero". O livro (Senra, 2010) foi uma resposta crítica a essa presunção. Cumpriu a intenção de mostrar o quanto havia sido pavimentado para que fosse possível a 
concretização, em prazo tão exíguo, de obra gigantesca. Um esforço que mobilizou o trânsito de milhares de trabalhadores, sobretudo os que deixaram as agruras do Nordeste em busca do novo, da oportunidade de encontrar um lugar que, por eles construído, poderia ser por eles habitado como cidadãos legítimos. Um longo percurso até 1953 pautou de forma mais sistemática o projeto de mudança da capital e a decisão pelo lugar onde se situaria. Ou seja, a aprovação do local em 1953 guarda uma história anterior, recuperada, tratada, exposta em toda sua complexidade.

A importância da publicação do IBGE (Senra, 2010) consiste na ampliação do escopo daquilo que deve ser selecionado como parte da recuperação histórico-sociológica de um evento como o da mudança da capital. 1948 é marco; 1953, igualmente. Mas, os textos iniciais do livro já mostraram: há muita água embaixo dessa ponte, entre o Brasil do sertão e o Brasil do litoral como ficou configurada a ligação feita pela nova capital.

O mesmo contraponto precisa alcançar a utopia de universidade. Desenhada com as linhas da imaginação e da paixão por perfeição, é confrontada com a rotina que demanda providências, ação continuada, cumprimento de promessas. Sobretudo, exige regularidade e previsibilidade. Duas condições estranhas ao voo da imaginação que convocou os integrantes a embarcarem na viagem intelectual que daria sentido às suas vidas.

\section{Tempo II:}

\section{a utopia chega ao gabinete}

Duas correspondências condensam a mensagem que proponho para esse segundo tempo de análise. Ambas das áreas das ciências exatas: a do matemático Alexandre Augusto Martins Rodrigues e a do físico Roberto Salmeron, autor de um dos livros mais importantes sobre a experiência da UnB (Salmeron, 1999). O matemático Alexandre Augusto Martins Rodrigues, em carta a Darcy Ribeiro, datada de 2 de outubro de 1963, já quebrava o som uníssono do romantismo universitário. Afinal, saímos das maquetes e adentramos os gabinetes! Em sua avaliação, a universidade não havia se esforçado o bastante para trazer para a UnB os melhores matemáticos brasileiros. Entre as razões que o atraíram para a universidade predominou a conviç̧ão de que aquela aventura consistia em um projeto sério de formação superior qualificada com cientistas e técnicos de alto nível do país. No entanto, prossegue:

Não me cabe a tarefa de planejar, organizar e convidar professores do futuro Instituto de Matemática, pois para isso designou a Universidade um coordenador. Presentemente conta o Departamento 
6. Em 26 de fevereiro de 1962, o Conselho Diretor da Fundação Universidade de Brasília cria a universidade cuja estrutura básica são os institutos centrais e as faculdades. Surge o Instituto Central de Matemática, cujo primeiro curso foi de pós-graduação em matemática coordenado Por Leopoldo Nachbin. Elon Lages o substituiu na coordenação logo após, em virtude de viagem de Nachbin ao exterior. Lages foi responsável pelo convite aos matemáticos Geraldo Ávila e Djairo Guedes de Figueiredo, recém-chegados do doutorado em Nova York, trazendo quatro instrutores que faziam disciplinas no mestrado do Instituto de Matemática Pura e Aplicada (Impa). Em abril de 1962, iniciam-se as aulas no Instituto Central de Matemática na UnB. de Matemática com dois únicos professores. Julgo que em nenhuma ocasião fez-se tentativa realmente séria de para cá trazer os matemáticos brasileiros mais qualificados. Djairo, Geraldo e eu não fomos convidados, oferecemo-nos para vir. Os instrutores foram atraídos por Djairo e Geraldo... (Rodrigues, 1963) ${ }^{6}$.

Ele não acredita que sua colaboração com o Departamento seja efetiva.

Anuncia sua pretensão de voltar a São Paulo. Ao longo de 1964, acreditava, o instituto poderia ser fortalecido com a volta dos brasileiros que estavam no exterior se aperfeiçoando e, em 1965, a UnB poderia contar mais efetivamente com a presença desses profissionais para a consolidação do instituto. Essa carta, no entanto, tem antecedentes no interior das relações entre professores do Departamento de Matemática. A Leopoldo Nachbin (1922-1993), considerado o mais representativo matemático brasileiro, notabilizado como membro fundador do Centro Brasileiro de Pesquisas Físicas (CBPF) e do Instituto Nacional de Matemática Pura e Aplicada (Impa) - duas referências de excelência no campo das ciências brasileiras -, foi atribuída a coordenação do que viria a se constituir como o Instituto de Ciência Matemática (ICM). O teor da correspondência sinaliza o tipo de tensão, disputa e frágil consolidação que campeavam nesta fase original da criação dos centros de referência dentro da universidade.

Em carta datada de 22 de setembro de 1963, dez dias antes da missiva que Alexandre Rodrigues dirigiu a Darcy Ribeiro, Nachbin manifesta sua dura crítica à decisão dos professores Djairo (Guedes de Figueiredo) e Geraldo (Severo de Souza Ávila) de deixarem a UnB, não querendo

dar agora um número grande e contínuo de anos de seus esforços ajudando outros jovens brasileiros a encontrarem o rumo certo em suas carreiras matemáticas. Ambos foram muito ajudados [prossegue Nachbin]. Imediatamente após terem terminado seus cursos no Brasil, gozaram quatro anos consecutivos de bolsas nos EEUU (1957-1961), dentro de um programa especial do CNPq proposto por mim, em 1956, ao tempo em que fui diretor do Setor de Pesquisas Matemáticas do CNPq. Candidataram-se em 1962, um ano apenas após terem regressado ao Brasil, a bolsas da Fundação Guggenheim. Achei isso prematuro: disse a ambos. Ouvido pela Guggenheim, dei parecer vivamente favorável à concessão dessas duas bolsas; mas apelei insistentemente junto a eles, para que ficassem quatro anos no Brasil, até 1965, ajudando os nossos jovens, enquanto outros brasileiros completavam o PhD em Matemática, regressando ao Brasil (Nachbin, 1963). 
Questão delicada considerada pelo missivista incompatível com a atitude de um profissional que havia recebido grande apoio do Brasil em sua formação, não se sentindo no dever de ajudar o país, em gesto de reciprocidade e responsabilidade. E o fato de, já em 1962, ter se candidatado à bolsa no exterior indicaria sua disposição planejada de abandonar o projeto do Departamento na UnB. Insatisfações no interior do campo profissional são registradas na correspondência em fase de dupla formação: a da própria universidade e a dos profissionais que se firmavam como intelectuais e cientistas em momentos distintos da formação acadêmica. A rotina exibia incongruências, vantagens consideradas indevidas e responsabilidades não assumidas, revelando diferenças e disputas no interior do grupo, processo que não escapou ao sociólogo Pierre Bourdieu quando formulou o conceito de campo intelectual como território de concorrência e disputa entre iguais.

A rotina de contratações, a formalização e a efetivação dos convites encontravam os embaraços para os quais o projeto original não havia se preparado para enfrentar. Há cartas de professores que se queixam do descompasso entre os esforços feitos para motivar jovens profissionais por aquela que seria a experiência universitária inovadora em um local distante dos grandes centros, mas aberto aos que se dispusessem a trabalhar e construir suas próprias áreas de especialização e o silêncio da administração central em efetivamente concretizar as contratações. Professores que teriam de se decidir por Brasília, renunciando a possibilidades de trabalho em centros de excelência, como a Universidade de São Paulo ou em algum centro internacional, cobravam informações precisas sobre condições de contrato, moradia, salário, apoio para trazer a família e fixar residência na capital federal. Este momento intermediário entre o ciclo fundador e o início da institucionalização é marcado na documentação por manifestações de descontentamento pela falta de segurança, de informação e de previsão a respeito de seus próprios envolvimentos como profissionais da universidade. O tempo da imaginação encontrava resistência nas rotinas de gabinete. Anísio Teixeira, reitor da UnB, era o alvo das sondagens e das perguntas dirigidas pelos interessados em compor a equipe de professores universitários.

À altura do funcionamento da universidade, Darcy Ribeiro já estava em outra ocupação. Foi ministro da Educação durante o regime parlamentarista do governo João Goulart, entre 18 de setembro de 1962 e 24 de janeiro de 1963, e chefe da Casa Civil, entre 18 de junho de 1963 e 31 de março de 1964. Ocupava o governo, se mantinha em Brasília, não mais à frente da universidade, tendo assumido a reitoria seu parceiro de antes, Anísio Teixeira. As cartas são dirigidas a Darcy e naturalmente que deveriam mesmo ser a ele dirigidas. Foi afinal quem convocou as mentes briIhantes para compor o quadro da universidade inovadora, para inventar o espaço da 
criação, da liberdade de pensamento e do avanço científico em todas as áreas. Mas quem acompanha a trajetória de Darcy Ribeiro toma contato com o impulso incontrolável pela invenção de projetos, pela defesa de causas, pela imaginação incontida no sentido de alterar rotinas consideradas tradicionais ou obsoletas - a Universidade de Brasília talvez tenha sido um dos mais fortes exemplos. Ela teria como missão virar a página da tradição universitária brasileira considerada emperrada, pesada, azeitada com procedimentos escorados em privilégios em vez de estímulo à incorporação de ideias, pessoas e projetos novos. Darcy encarna em sua figura pública o dilema sociológico implicado na institucionalização de procedimentos, o que supõe permanência, planejamento, transparência, antecipação de providências, cálculo para estabelecimento dos passos esperados na constituição das rotinas. A continuidade de gabinete soa empobrecimento e provoca impaciência em uma personalidade tão independente e ambiciosa quanto a do intelectual engajado em causas e avesso aos vícios do dia a dia. Além disso, as cidades são e serão sempre "artefatos culturais inacabados" porque são obras que transitam por gerações e gerações (Madeira, 2013). Criam e sofrem os efeitos do tempo, das vontades, das conjunturas e das forças nem sempre consonantes. A interrupção violenta com o Golpe de 1964 e o recrudescimento da repressão que a ele se sucedeu acabaram fortalecendo os impasses esperados em todos os processos de tamanha complexidade como a que implicava a montagem de uma universidade como a que se previa.

Tempo III:

a distopia de nação refaz a universidade

No dia 9 de abril de 1964, nove dias depois do golpe de Estado, tropas do Exército e da Polícia Militar de Minas Gerais invadiram o campus da universidade, com manobras que davam a impressão de estarem tomando uma fortaleza. Foram transportadas por 14 ônibus e acompanhadas de três ambulâncias, demonstração óbvia de que esperavam resistência armada. Os invasores ficaram surpresos ao constatar o ambiente de trabalho que encontraram... (Salmeron, 2015).

O Golpe de 1964 trouxe anos difíceis para a UnB. Mais perto, no epicentro do poder, a instituição foi das mais atingidas pela ação da repressão. Perseguição a professores e a estudantes acabou sendo rotina, alterando a vida universitária de forma aguda. A primeira invasão aconteceu em 9 de abril de 1964. O reitor e o vice-reitor, Anísio Teixeira e Almir de Castro, respectivamente, foram surpreendidos por tropas do Exército e por policiais de Minas Gerais. Há informações de que os militares invadiram salas de aula, revistaram estudantes, buscavam armas e materiais de propaganda subversiva; procuravam 12 professores que deveriam 
ser detidos e interrogados; interditaram a biblioteca e as salas de trabalho dos professores. Depois desta invasão, Tanto Anísio Teixeira como Almir de Castro foram demitidos. O governo militar nomeou para reitor pro tempore, o professor de medicina veterinária da USP, Zeferino Vaz, cujo mandato foi de 13 de abril de 1964 a 25 de agosto de 1965 .

Mas, a despeito dos atos decorridos em função do Golpe de 1964, a Universidade de Brasília manteve ainda a aura de universidade experimento para onde olhares e interesses se voltavam como campo possível à inovação. Roberto Salmeron faz menção ao número expressivo de professores que o procuravam interessados em integrarem o corpo docente da universidade. Mesmo com a nomeação pelos militares de Zeferino Vaz, prevalecia a convicção de que aquele era um espaço destacado pela maneira como fora concebido, pelas ousadias ali ensaiadas e pelos desafios que anunciava para enfrentar a burocratização e o excessivo formalismo. Mas os sinais de repressão foram ficando mais e mais acentuados com uma caça ao que fosse identificado como vestígio de comunismo - o que poderia ser encontrado em diversos espaços por distintos indícios. Um dos primeiros atos do reitor foi demitir nove professores: José Albertino Rosário Rodrigues, Perseu Abramo (setor de sociologia); Edgard de Albuquerque Graeff, Eustáquio Toledo Machado Filho e José Zanini Caldas (curso de arquitetura e artes); Francisco Heron de Alencar (Departamento de Letras); Jairo Simões (direito); Lincoln Ribeiro e Ruy Mauro de Araújo Marini (política).

De abril de 1964 a outubro de 1965, a universidade foi sendo progressivamente encurralada por medidas crescentes de repressão. O fato de estar situada no epicentro do poder facultou muitas das ações intervencionistas no campus. Ainda que conferido pelos professores um "voto de confiança" aos dois reitores interventores nomeados, Zeferino Vaz e seu sucessor Laerte Ramos de Carvalho pela manifestação inicial de preservar o projeto original da universidade, os desdobramentos de ambas as gestões foram recrudescidos pela onda repressiva que assolava a vida política do país ${ }^{7}$. As consequências sobre a comunidade universitária foram duras com perseguições, demissões, com devolução de professores a cargos administrativos que exerceram anteriormente, forma de impedir sua função de magistério, caça a indícios de subversão (Cunha, 2007).

O ano de 1965 registrou mais uma invasão. Setembro foi marcado por uma greve do corpo docente por 24 horas. Uma greve em resposta à demissão dos professores Ernani Maria de Fiori, Edna Soter de Oliveira e Roberto Décio de Las Casas, sob a alegação de "conveniência da administração". Já estava em vigor a reitoria de Laerte Ramos de Carvalho, nomeado em 25 de agosto de 1965, com mandato estendido
7. No documento citado anteriormente em que Darcy Ribeiro concede entrevista aos pesquisadores (Ribeiro, 1978c), há uma avaliação feita por ele bastante desigual com relação aos dois reitores que a universidade recebeu pós-64. Embora faça menção ao conservadorismo de Zeferino Vaz, acentuou sua competência em manter a universidade e protegê-la da destruição, ao contrário da referência bastante negativa que destinou a Laerte Ramos de Carvalho nos termos adjetivados e cortantes que caracterizaram as falas de Darcy. 
a 3 de novembro de 1967. Instaurou-se o clima de apreensão continuada entre os que ficaram sob vigilância, à espreita de ações arbitrárias. Laerte Ramos de CarvaIho, diante da movimentação que incluía professores e estudantes, solicitou envio de tropas militares ao campus da universidade dando lugar à segunda invasão, na madrugada de 11 de outubro de 1965. A ação militar impedia a entrada e saída do campus, bloqueava ainda a entrada nos laboratórios para prosseguimento de atividades de pesquisa ali em andamento. Quinze dias depois, o reitor demitiu 15 professores, atribuindo a eles a responsabilidade pelo clima de subversão da ordem. As demissões foram justificadas como "medida disciplinar". Entre os demitidos estava Sepúlveda Pertence, mais tarde, presidente do Supremo Tribunal Federal. Em reação a esta medida, 223 dos 305 professores da universidade demitiram-se. Assim descreveu Roberto Salmeron: "Chegara o momento em que devíamos escolher com lucidez entre somente duas alternativas: aceitar as interferências externas ou recusá-las". Cerca de 80\% dos professores decidiram recusar. Em 18 de outubro, a universidade que acabara de nascer perdia a maior parte dos cérebros selecionados para construir a instituição de vanguarda idealizada por Darcy Ribeiro. As ações de repressão que atingiram a Universidade de Brasília foram bem dimensionadas por Rodrigo Patto Sá Motta:

O tratamento violento dispensado à UnB explica-se pela imagem que a jovem universidade (fundada em 1962) tinha nos meios conservadores. Ela era considerada um antro de comunistas reunidos pelo marxista Darcy Ribeiro, um de seus fundadores, com o objetivo de desencaminhar a juventude brasileira. De fato, entre os professores contratados pela UnB, havia gente de esquerda, incluindo alguns intelectuais ligados ao PCB, como Oscar Niemeyer, Claudio Santoro e Fritz Teixeira de Salles, por exemplo. Porém, para os defensores do projeto da universidade, a presença de professores de esquerda era coincidência, e não fruto de um plano perverso. Haveria uma convergência entre os fatores juventude, simpatia por reformas sociais e entusiasmo pelo projeto acadêmico arrojado da UnB. De qualquer forma, a imagem de ninho de subversão era francamente exagerada, pois a maioria dos professores não tinha militância política. Os receios que a UnB gerava deviam-se, em parte, à ousadia e à audácia do seu projeto, pois fora planejada para servir de ponta de lança para a reforma das universidades brasileiras (Sá Motta, 2014: 32).

No entanto, o ano de 1968 estava por vir. E com este ano, emblemático na história política brasileira, veio igualmente a Reforma Universitária que mobilizou os principais ambientes universitários do país com estudantes e professores em discussão permanente sobre o modelo que deveria presidir a vida universitária brasileira. A experiência da Universidade de Brasília foi precursora do que viria, em muitas di- 
mensões, se institucionalizar com a Reforma de 68. Uma reforma que ficou marcada pela forma como foi implantada. Sob o regime militar e em cenário cada vez mais opressor, ela perdeu muito do que a animava e até mesmo do que a justificava antes mesmo do golpe de 1964 (ver Bomeny, 1994a).

O ambiente político se polarizava em todo o país. A alta do preço da comida no restaurante universitário Calabouço, no Rio de Janeiro, anunciada para o dia 28 de março de 1968, provocou o protesto dos estudantes e a organização de uma passeata relâmpago. Ao reagir à ação dos militares, estudantes se abrigaram no restaurante e responderam à repressão arremessando paus e pedras, levando os militares a recuarem. O retorno das forças policiais recrudesceu o confronto levando à morte um dos estudantes: Edson Luís de Lima Souto. O movimento ultrapassou o Rio e alcançou estudantes da UnB. Reunidos na praça localizada entre a Faculdade de Educação e a quadra de basquete, três mil estudantes protestavam com palavras de ordem contra a repressão continuada que fez como vítima o jovem estudante no Rio de Janeiro. Esse foi o estopim para o decreto da prisão de sete universitários, entre eles, o líder estudantil Honestino Monteiro Guimarães, morto pela repressão em 1971.

O episódio da morte de Edson Luís no Rio de Janeiro já foi objeto de várias pesquisas no âmbito do regime autoritário no Brasil. Foi mesmo considerada como detonadora do movimento estudantil que àquela altura passava por ligeiro descenso, abalado pelas ações de repressão aos estudantes, fechamento da União Nacional dos Estudantes (UNE) pelas forças da repressão. O movimento retomou fôlego movido por sentimento de protesto contra a morte do estudante provocada pela invasão da polícia e do confronto no interior do Calabouço. O corpo do estudante foi levado para a Assembleia Legislativa do Rio de Janeiro, onde foi velado por uma multidão que acompanhou o cortejo fúnebre tomando ruas e reunindo milhares de pessoas.

Com a posse do professor, doutor em física e oficial da Marinha, José Carlos de Almeida Azevedo, em maio de 1976, as manifestações recomeçaram na UnB. Um ano após a mudança na reitoria, multiplicaram-se os protestos de alunos contra a má qualidade do ensino, a ociosidade nos laboratórios e a falta de professores. A crise política da UnB ultrapassou os limites do campus. O Senado criou uma comissão para interferir no conflito. Cerca de 150 professores entraram como mediadores entre a reitoria e os estudantes. Novamente, em seis de junho de 1977, tropas militares invadiram a UnB, prenderam estudantes e intimaram professores e funcionários. Desta vez, o estopim foi a greve que estudantes e professores declararam para dar um fim às agressões que sofriam. "Foi uma luta pela dignidade da UnB, para dizer 
que aqui não aceitaríamos mais esse tratamento", explica Antônio Ramaiana Ribeiro (2009), engenheiro, formado pela UnB, autor do livro UnB 1977: O Início do Fim. Ao se valer de documentos, fotos e matérias que saíram na imprensa, Ramaiana Ribeiro relata a reorganização do movimento estudantil desde 1976. A eclosão do movimento veio com um manifesto: o Dia Nacional de Luta contra Prisões Arbitrárias, em 19 de maio de 1977. Descreve a atmosfera que inspirou o livro como cenário de repressão, tendo o "capitão de mar e guerra José Carlos Azevedo" à frente da reitoria. A punição dos estudantes por participarem do protesto resultou na greve dos alunos exigindo o fim das punições e a saída do reitor. Quatro meses de paralisação e repercussão no noticiário nacional foram responsáveis pela classificação do movimento como um dos mais importantes desde 1968.

As invasões só acabaram com o início da abertura política no Brasil. Em 1979, o Congresso aprovou a Lei de Anistia que perdoou os crimes políticos cometidos desde 1961. A democracia na universidade é retomada em 1984, com a eleição do reitor Cristovam Buarque.

\title{
Epílogo
}

\begin{abstract}
Só muito lentamente, ao longo de sofridas décadas, essa nossa Universidade de Brasília começa a renascer. Isso se dá pelo trabaIho recôndito, silente, daqueles que se fizeram aqui o sal de sua carne. Retomaram nosso ideal de implantar nesta cidade-capital do Brasil uma comunidade autônoma e independente de sábios capazes de operar em duas órbitas. A de dominar todo o saber humano, para ganhar existência própria dentro da comunidade científica mundial, tarefa indispensável para que o Brasil realize as suas potencialidades. E também a de acercar-se ao nosso povo mais humilhado e oprimido para buscar os caminhos de sua libertação e prosperidade (Darcy Ribeiro, 15 de março de 1995).
\end{abstract}

O sonho de uma universidade modelo nasceu como resposta ao diagnóstico crítico que Anísio Teixeira e Darcy Ribeiro compartilharam a respeito do sistema universitário brasileiro. Projeto ambicioso, pensado no momento efervescente da construção da nova capital, quando estiveram em pauta esforços de convencimento a respeito da construção de um plano de integração do Brasil Central. A despeito de todas as reações desconfiadas sobre o acerto de uma decisão de tal magnitude, e do sucesso que se poderia esperar de um desenvolvimento pelo interior, a capital foi tomando forma, e com ela, o que seria uma universidade modelo, nascida da experiência e do desejo de reparação do destino de outra iniciativa, resgatada pela memória como de igual vigor, interrompida pela força do autoritarismo. A Universidade de Brasília teria a marca de um experimento de ensino superior pensado no contexto de re- 
formulação da educação básica, da democratização do ensino com a campanha em defesa da universalização da educação pública gratuita, leiga e de tempo integral à população em idade escolar, independentemente de status social e da situação econômica. A UnB nascia no contexto de extensão do movimento da Escola Nova, da mesma maneira que a Universidade do Distrito Federal (UDF), na década de 1930, havia sido concebida na atmosfera da inovação, da descentralização, da democratização do ensino superior. Os ataques desferidos contra ela no regime militar são uma evidência do quanto se mostrava diferente do usualmente conhecido como estrutura universitária em nosso país. A utopia democrática invadira a universidade; a intolerância autoritária impôs-Ihe o cerceamento à liberdade e à flexibilidade que foram suas marcas de nascimento. Entre um e outro processo, a rotina institucional retirou-lhe o brilho do entusiasmo que capturou o interesse e a disposição de profissionais que se deslocaram dos mais distantes centros em nome da fundação de algo completamente novo. Darcy Ribeiro manteve a convicção do espírito que presidira a criação da universidade sempre que a ela se referia. Em 1990, com a publicação de Testemunho, trouxe para o leitor a memória de uma homenagem recebida em 1979 com o título de "Doutor honoris causa", concedido pela Sorbonne. Deixa registrado o desafio que foi escrever um discurso para ser pronunciado na ocasião. Pois está lá a convicção do que deveria distinguir o projeto da Universidade de Brasília frente às experiências mais convencionalmente instituídas:

\begin{abstract}
O desafio foi quase paralisante. De fato, nunca tive tanta dificuldade de escrever um discurso. Dois eram os obstáculos. Por um lado, não queria fazer o elogio da Sorbonne em seu papel de suposta avó das universidades ou de mãe fecunda da cultura ocidental. Tenho planejado a universidade de Brasília, repensando a universidade desde a raiz, não podia cair em basbaquices. A outra dificuldade era não fazer elogio da antropologia francesa, especialmente de Lévi-Strauss, tão admirado e papagaiado por toda parte, principalmente aqui, por uma antropologia desumana, insensata e infiel... (Ribeiro, 1990: 13 apud Coelho, 2009: 94).
\end{abstract}

O caráter de balão de ensaio deixou marcas. A universidade anteciparia a Reforma de 1968, sobretudo no artigo que a própria Lei de Diretrizes e Bases da Educação Nacional (LDB), de 1961, havia mantido por resistência daqueles que perderiam com a alteração: o sistema de cátedra que acarretava tantas críticas, e que foi matéria de inúmeras manifestações ao longo da década de 1950 e início da de 1960. A UnB, portanto, inovava em sua exceção. Já fora concebida sem a admissão de catedráticos. A aposta dos idealizadores, sobretudo de Darcy Ribeiro, foi que ela não seria domesticável nem pela tradição que enrijecia e mantinha privilégios a uns poucos, nem pelo sistema regressivo e repressivo que se montou com o regime militar. Teria o mito fundador de sua existência força inspiradora para interpelar criticamente o 
inevitável e decorrente processo de institucionalização em suas rotinas nem sempre mantidas à luz da criatividade e da autonomia? Esta talvez seja a questão sociológica permanente a provocar a imaginação daqueles que se empenham na avaliação distanciada do sistema universitário.

Abstract: The article deals with the foundation of the University of Brasilia and Darcy Ribeiro's impact in it. It identifies three moments in the history of the University, corresponding to three different timings in the University's trajectory: utopia times, bureaucracy times, and dystopia times.

Keywords: Universidade de Brasília, Darcy Ribeiro

\section{Referências}

BOMENY, Helena. Darcy Ribeiro. Sociologia de um indisciplinado. Belo Horizonte: Editora UFMG, 2001.

A reforma universitária de 1968: 25 anos depois. Revista Brasileira de Ciências Sociais, v. 9, n. 26, p.51-65, Out. 1994a.

—. Guardiães da razão: modernistas mineiros. Rio de Janeiro; São Paulo: Editora UFRJ; Tempo Brasileiro, 1994b.

BRANDÃO, Gildo Marçal. Ideias e intelectuais: modos de usar. Lua Nova, n. 54, 2001. CARVALHO, Maria Alice Rezende de. Temas sobre a organização dos intelectuais no Brasil. Revista Brasileira de Ciências Sociais, v. 22, n. 65, p. 18-31, Out. 2007.

COELHO, Haydée Ribeiro. Darcy Ribeiro e outros atores: interseções no diálogo França-Brasil. O eixo e a Roda, v. 18, n. 1. Belo Horizonte, 2009.

CUNHA, Luiz Antonio. Universidade reformada: o golpe de 1964 e a modernização do ensino superior. São Paulo: Editora Unesp, 2007.

GORELIK, Adrián. Das vanguardas a Brasília. Cultura urbana e arquitetura na América Latina. Belo Horizonte: Editora UFMG, 2005.

KUBITSCHEK, Juscelino. Por que construí Brasília. Brasília: Senado Federal, 1998.

LIMA, Nísia Trindade. Um sertão chamado Brasil: intelectuais e representação geográfica da identidade nacional. Rio de Janeiro: Instituto Universitário de Pesquisas do Rio de Janeiro; Universidade Cândido Mendes; Revan, 1999.

MADEIRA, Angélica. Itinerância dos artistas. A construção do campo das artes visuais em Brasília 1958-2008. Brasília: Editora UnB, 2013. 
MAIA, João Marcelo. "As ideias que fazem o Estado andar: imaginação espacial, pensamento brasileiro e território no Brasil Central". Dados, Revista de Ciências Sociais, v. 53, n. 3, p. 621- 655, 2010.

MOURA, Flávio. Mário Pedrosa e o neoconcretismo: a centralidade de um projeto crítico. Novos Estudos - Cebrap, n. 99. São Paulo, Jul. 2014; Disponível em: <http:// dx.doi.org/10.1590/s0101-33002014000200008>.

NACHBIN, Leopoldo, Carta a Darcy Ribeiro em 22 Set. 1963. Documento do Acervo Darcy e Berta Ribeiro. Memorial Darcy Ribeiro/Fundar. Universidade de Brasília, Brasília [Nachbin, DR id/1959.08.06, v.4/3. P.1], 1963.

OLIVEIRA, Francisco de. Intelectuais, conhecimento e espaço público. Conferência de abertura da 24a Reunião Anual da Anped. Revista Brasileira de Educação, n. 18, p. 125-132, Set.-Dez. 2001.

OLIVEIRA, Marcio de. O Iseb e a construção de Brasília: correspondências míticas. Sociedade e Estado. v. 21, p. 487-512, Maio/Ago. 2006.

RAMAIANA RIBEIRO, Antônio. UnB 1977: o início do fim. Brasília: Paralelo 15, 2009. RIBEIRO, Darcy. Testemunho. São Paulo: Siciliano, 1990.

—. A universidade necessária. Rio de Janeiro: Paz e Terra, 1978a.

—. UnB: invenção e descaminho. Rio de Janeiro: Avenir Editora, 1978b.

—_. Entrevista com o professor Darcy Ribeiro. Entrevistadores: Tjerk G. Franken, Maria Clara Mariani, Márcia Bandeira de Mello Leite Nunes, Maria Tereza Lopes e Carla Costa. Documento do Acervo Darcy e Berta Ribeiro. Brasília: Memorial Darcy Ribeiro/Fundar, [DR/Ribeiro, D; pi/ 1978.02.15; 78pp], 1978c.

— Teoria do Brasil. Rio de Janeiro: Civilização Brasileira, 1975.

- Documento do Acervo Darcy e Berta Ribeiro. Memorial Darcy Ribeiro/Fundar, [DR/Ribeiro, D; id/1959.08.06, v.9/4, p.6], 1959.

RIDENTI, Marcelo. Artistas e política no Brasil pós-1960: itinerários da brasilidade. In: RIDENTI, Marcelo; BASTOS, Elide Rugai; ROLLAND, Denis (Orgs.). Intelectuais e Estado, p. 229-262. Belo Horizonte: Editora UFMG, 2006.

. Intelectuais e romantismo revolucionário. São Paulo em Perspectiva, v. 15, n. 2, p. 13-19, 2001. 
RODRIGUES, Alexandre Augusto Martins. Carta a Darcy Ribeiro, 2 Out. 1963. Documento do Acervo Darcy e Berta Ribeiro. Brasília: Memorial Darcy Ribeiro/Fundar, 1963.

SALMERON, Roberto. Discurso proferido ao receber o título de doutor honoris causa pela Universidade de Brasília. Brasília: Universidade de Brasília (UnB), 19 Out. 2005. . A universidade interrompida. Brasília: Editora UnB, 1999.

SÁ MOTTA, Rodrigo Patto. As universidades e o regime militar. Rio de Janeiro: Jorge Zahar Editor, 2014.

_. Em guarda contra o "perigo vermelho". O anticomunismo no Brasil (19171964). São Paulo: Perspectiva, 2002.

SILVA, Agostinho. Carta a Darcy Ribeiro, datada de Salvador, 27 Maio 1960. Documento do Acervo Darcy e Berta Ribeiro. Brasília: Memorial Darcy Ribeiro/Fundar, 1960.

SENRA, Nelson de Castro (Org.). Veredas de Brasília. As expedições geográficas em busca de um sonho. Brasília; Rio de Janeiro: Ministério do Planejamento; Instituto Brasileiro de Geografia e Estatística (IBGE), Centro de Documentação e Disseminação de Informações, 2010.

VILLAS BÔAS, Glaucia K. Os dois lados do concretismo. In: REINHEIMER, Patrícia; SANT'ANNA, Sabrina Parracho (Orgs.). Reflexões sobre arte e cultura material, p. 73-88. Rio de Janeiro: Folha Seca, 2013. 